\title{
EDITORIAL
}

\section{The soul of caring}

\author{
Mike Shooter
}

'It is the province of knowledge to speak and it is the privilege of wisdom to listen.'

(Oliver Wendell Holmes, American physician, poet and essayist in the Poet at the Breakfast Table (1872), Chapter 10)

Reflecting on Rowan Williams' salute to 'intensified listening' as the most distinctive feature of psychiatric care (Williams, 2005), I was taken back to an experience with one of my sons. Forgive me if you have heard me tell the story before. But that is the nature of stories and every time it's a little different.

Ben had done what I did - completed a previous degree and earned good money in the outside world before deciding to go back and read medicine. He enrolled himself as a nurse in a geriatric hospital and asked me to fix him up with a variety of consultant attachments so that he could prove his motivation to the entry panels at medical school. When it came to psychiatry, he travelled around with me.

After a fortnight in some of the most deprived valleys of south Wales, he confessed himself dumbfounded by the attempts of families to find a foothold among a scree of violence, alcoholism, drug addiction and child abuse, sliding all to easily into a pit of despair. 'But do you mind if I ask you a daft question?' he said, as we sat in a pub at the end of the day. 'What is it that you do?' Trying hard not to be offended, I asked him what he thought I did. 'Just listening I suppose... .'

'Just listening', I told him, was the most difficult skill he would ever learn and the easier it looked the more skilful it would be. The next day I set him a task. I asked him to tell me everything that he had learnt from what the first family had said. Listening with his ears. No problem there. I asked him to tell me everything he had learnt about the second family by how they related to each other. Listening with his eyes. More difficult. Finally, I asked him to tell me all he knew about the third family by how they made him feel. Listening with his heart. Very difficult indeed.
Many months later, after examining his first patient at medical school, Ben reminded me of that day. 'You forgot one,' he said excitedly, '- listening with your hands.' And so I had. The physical examination, old-fashioned though it may be in these days of scans and blood cultures, is a conversation between the physician's hands and the patient's body, at once diagnostic but assuring, intimate and utterly respectful - Williams' practice of 'feeling the way into the world' in a very literal sense. Not for nothing do both priest and doctor talk of the laying on of hands.

All this, of course, is fraught with problems. To listen with such intensity to our patients, and learn from them about their needs, we must stagemanage our own feelings, so that they do not come between us and the patient's story. But that story may be painful to hear. Small wonder that some doctors retreat behind a barrier of paternalism - be that medication or Delphic interpretation, bestowed upon the bewildered patient by a Pythian interpreter of the doctor's, not the patient's, wishes. Small wonder that some doctors overwhelm their patients with a hedonistic desire to join with them in their distress that has more to do with their own story than that of the patient. And the same, you might think, could be said of some members of the priesthood.

I know nothing of training for the priesthood, but I fear that our own training, in a world of technology, superspecialism and quick results, teaches us little about how to conduct ourselves in a close and longterm relationship. Is it surprising that psychiatrists who have never been shown how to mould the 'shape' of a relationship, to appear warm and approachable within proper boundaries, and to handle concepts such as transference and countertransference should find themselves so often at the steps of the General Medical Council?

Which brings us to the wider issue of expertise and the responsibilities that go with it. Patients are experts by experience in their own story. The need for psychiatrists to develop an ear for that story is

Mike Shooter is a consultant in child and adolescent psychiatry with Gwent Healthcare NHS Trust (The Children's Centre, Neville Hall Hospital, Brecon Road, Abergavenny NP7 7EG, UK. E-mail: jennifer.bendon@gwent.wales.nhs.uk). At the time of writing, he was President of the Royal College of Psychiatrists. 
the whole point of Williams' argument and mine. It is what patients and their carers say they search for most in their journey through the mental health system. But they may come to get more concrete things from us too. Sometimes this is straightforward advice, distilled from many other patients with similar stories. Sometimes this is the best knowledge available, the balance between therapeutic and sideeffects of medication for example, on which patients can make a reasoned judgement for themselves. Sometimes it is the skilful interpretation of rigid patterns of behaviour that unlocks past trauma and helps the patient to face the future 'without a wardrobe of excuses' (Auden, 1966).

In all of that, and especially where the patient is learning-disabled, a child or an old person, we must be careful to assume that they have capacity to make decisions unless proved to the contrary - the principle that underlies the proposals for a new Capacity Act. But psychiatrists, of course, have an added responsibility - having listened carefully to the circumstances, to take make decisions in a patient's best interests where their illness has temporarily so clouded their judgement that they are incapable of making decisions for themselves. Such a responsibility is part of the trusting therapeutic relationship; to shirk it may be as harmful as to impose it where it is not warranted.

Ay, there's the rub! None of us, priests or doctors, exercise our skills and responsibilities in a vacuum. All of us have taskmasters whom we must satisfy, and some are harder taskmasters than others. For all I know, Williams' God may be an authoritarian figure: 'Not thy will but mine be done!' But I wouldn't mind betting that, in the last resort, $\mathrm{He}$ (or She) leaves it to the Archbishop to tend his flock according to his own conscience. Not so our government. Despite the recommendations of a Joint Select Committee (Joint Committee on the Draft Mental Health Bill, 2005), the government's proposals for Mental Health Act reform may yet pay more attention to public myths about risk than the wishes of patients and their carers. Would that politicians listened as intensely to what we have to say, and act upon it, as we would to our patients.

So, finally, to what Williams calls the 'language of the encounter'. As a child and adolescent psychiatrist, I have some patients who do not wish to be understood - merely to criticise me for not understanding. They have a Job-like view of the world and it matters not 'if devastation comes at the hands of marauding Chaldeans or a great wind from the desert. Each belongs to a world that is, as usual, opposed to us' (Neiman, 2002: p. 237). I am equally sure that there are patients who come to us neither to be understood nor to understand but to bathe in the high-church 'magic' of the relationship with a psychiatrist who is, at this point, more priest than doctor. We underestimate that rôle at our peril.

But for the majority of patients, a prerequisite of the process of intensified listening will be the search for a language in which the patient feels able to express him- or herself and the psychiatrist is able to understand. Sometimes this may need, quite literally, a skilful translator. Sometimes the psychiatrist will need to interpret the non-verbal language in which some cultures and age groups couch their emotional distress. A pain in the chest may be a symptom of a broken heart in more ways than one. Sometimes the search is for common ground at its most basic level.

I started with a story from the Valleys and I will end with another. For many months I drove up to the head of the Rhondda to see a young disabled lad, who waited for me in a wheelchair and a cloud of gloom. I understood his unhappiness, but I felt totally unable to find with him a future that his past had robbed him of. Then I discovered that he liked bird-watching. He was excited by the idea of a pair of peregrine falcons that had nested up the valley side and were killing the local pigeons, one by one. So I carried him up the mountain to find them. Our own 'common ground'.

It became a ritual. We never did see the falcons, but in the talk about them, and in the silence that we let grow more easily between us, we found a way of working together through his feelings about himself and the outside world. I have no idea how much that cost. Totally uneconomic. I have no idea how its effect could be measured. Totally unstatistical. I have no idea how that relationship would fit within ethical foundations. Totally unprofessional.

What I do know is that, as I jogged down the valley for the last time, with Owen on my shoulders, I felt something swoop low over the horizon and seize our feathered lives by the neck with a fierce grip of hope.

\section{References}

Auden, W. H. (1966) In Memory of Sigmund Freud. Collected Shorter Poems 1927-1957. London: Faber \& Faber.

Joint Committee on the Draft Mental Health Bill (2005) First Report (HL Paper 79-I/HC 95-I). London: Stationery Office. http://www.publications.parliament.uk/pa/jt200405/ jtselect/jtment/79/7902.htm

Neiman, S. (2002) Evil in Modern Thought: An Alternative History of Philosophy. Princeton: Princeton University Press.

Williams, R. (2005) The care of souls. Advances in Psychiatric Treatment, 11, 4-5. 